\title{
Competency based Public Health Training in Undergraduate Medical Education - Much needed Paradigm Shift in India
}

\author{
Pandav, C.S., Zodpey, S., Negandhi, H., Yadav, K., Salve, H., Kumar, R
}

\begin{abstract}
Although medical colleges are the traditional hub for creating public health professionals within India, several gaps exist in the public health training across undergraduate medical programs. The development of a competency framework for public health professionals was undertaken as part of an activity of the Indian Public Health Association. The activities included a secondary review of literature, and iterative discussions across two rounds of workshops. We identified the list of functions and topic areas for MBBS graduates in the public health domain which will need to be incorporated in MBBS syllabi. State medical councils will have to take the leadership to identify and modify public health functions and initiate work on development of competency frameworks under the guidance of a central expert committee at the national level.
\end{abstract}

Key words: Curricular development; competencies; public health functions; undergraduate medical education; MBBS

\section{Background}

Medical colleges are the traditional hub for creating public health professionals within India (Negandhi, Sharma et al. 2012). These colleges in India train as much as 49,668 MBBS graduates annually ( $\mathrm{MCl} 2013$ ) and all of them undergo a compulsory training in preventive \& social medicine/ community medicine during their undergraduate years as mandated by the Medical Council of India. Additionally, there are public health schools in India that are housed in selected medical and non-medical institutes. They provide opportunities to undertake Masters programmes in public health (Negandhi, Sharma, et al. 2010).

\footnotetext{
Corresponding Author:

Professor Sanjay Zodpey

Vice-President [North],

Public Health Foundation of India

Plot No.47, Sector-44,

Institutional Area

India

Email:Sanjay.zodpey@phfi.org
}

Emergence of public health schools across India is however, a relatively recent occurrence (Zodpey, Sharma, et al. 2011) and these public health schools produce less than 1000 graduates annually. In such a situation, undergraduate medical education programs (MBBS) produce the largest number of graduates with formal training in public health and therefore, MBBS doctors continue to be the mainstay of public health service delivery within the country.

Despite the long history of training in preventive \& social medicine/ community medicine under undergraduate medical programs in India, many gaps still exist. These gaps are related to outdated curricula, absence of a standardised list of public health competencies, predominant didactic pedagogy and poor linkages with health systems (Zodpey, Sharma et al. 2011). The gaps may be the result of lack of originality in thinking and training approaches across faculties and departments engaged in teaching community medicine (Shewade, H.D., Jeyashree, K., et al. 2014). The situation is also compounded by lack of agreement within academic circles about the nomenclature, vision and the focus of the 
academic programs covering public health education.

Producing competent professionals is an important prerequisite to achieve good primary health care outcomes. A rational approach to produce such professionals would be to develop training programmes based on relevant competencies. Competencies can be defined as an observable or measurable performance, skill, knowledge and attitude related to a particular domain or discipline of public health. The curriculum must be designed to facilitate the acquisition of these competencies by individuals, thereby helping in the delivery of desired services.

The Lancet Commission Report too has highlighted the need for competency based public health training (Frenk, Chen et al. 2010). The report emphasises that currently, there is mismatch between professional competencies and patient and population priorities because of fragmentary, outdated, and static curricula producing ill-equipped graduates from underfinanced institutions. Transformative learning has been highlighted by the report as an important educational principle which should underpin health professions' training curricula. Transformative learning involves three fundamental shifts: from fact memorisation to searching, analysis, and synthesis of information for decision making; from seeking professional credentials to achieving core competencies for effective teamwork in health systems; and from non-critical adoption of educational models to creative adaptation of global resources to address local priorities (Frenk, Chen et al. 2010). Against this background, discussions on competencies and ways of ensuring their acquisition by MBBS students has become very important.

In 2009, a national consultation on public health workforce organized by the ministry of health and family welfare, government of India, and WHO country office in New Delhi sought to review and share current status of public health workforce development in India to make the public health education and training more relevant to India's needs. During this consultation, necessity of a competency based public health curriculum for undergraduate medical education in India was outlined. The Indian Public Health Association (IPHA) with support of WHO India Office undertook the task of identifying competencies for undergraduate medical education in India.

\section{Methodology:}

The development of a competency framework for public health professionals was undertaken as part of an activity of the Indian Public Health Association in the year 2011-2012.

The activities began with a literature search to understand the rationales and origins of competency frameworks in education and public health in particular and to perform a situation analysis. Published evidence, both globally and in India was included in the literature search. Search engines included Google Scholar, Pubmed, and IndMed with key words "public health"; "competency" and "frameworks". Websites of National Institute of Health \& Family Welfare, Medical Council of India, All India Institute of Medical Sciences- New Delhi (AIIMS), Post-graduate Institute of Medical Education \& Research - Chandigarh, Institute of Health Management Research - Jaipur, Public Health Foundation of India - New Delhi, Rajiv Gandhi University of Health Sciences - Bangalore and other major public health institutes in India were also searched for existing public health training programme and curricula. Manual search was done in B B Dikshit library, AlIMS, National Medical Library - New Delhi and libraries of other public health institutes to retrieve various published papers, documents, manuals and reports related to public health training in India. Experts working in the field of public health were contacted to retrieve related information from them. This was followed by the creation of a summary of the global and Indian efforts towards the development of competency frameworks in public health.

Subsequently, a group of public health experts was identified on the basis of their contribution to academics, in health systems and experience of research work. The identified experts were given the task of formulating competencies for public health training programmes in undergraduate medical curricula in India. Accordingly, this expert 
group interacted over a period of three months through face-to-face meetings and online media. The group was expected to list the public health functions of in-service doctors with an MBBS qualification and design competency statements for core competencies required for performing specific public health functions. Experts worked in small groups which focused on specific sub questions of the larger study and the work format adopted by the group enabled experts to develop recommendations based on a consensus reached among them.

\section{Results:}

Need of competency based public health training

Competency based public health education may improve the health of the public by encouraging service delivery that is evidence based, population-focused, ethical, equitable, standardized and client-centred; helping to explain the nature of public health and public health goals (Public Health Agency of Canada 2008). Globally, competencies have been developed from the perspective of Academic programmes; Public health functions; or competencies for the level at which public health professionals work within the health system. Professional public health programs in India do not have explicitly stated competency based curricula. This is further complicated by variable quality of existing programs, lack of specialization in key public health domains and an underexplored scope of distance education.

Identification of public health functions, curriculum content and competencies

Table 1 lists the public health functions expected of MBBS graduates that were identified through the study. Table 2 maps the MBBS curricular content areas (which can be expected to cover these competencies) to these functions.

\section{Table 1: Public health functions expected of MBBS graduate}

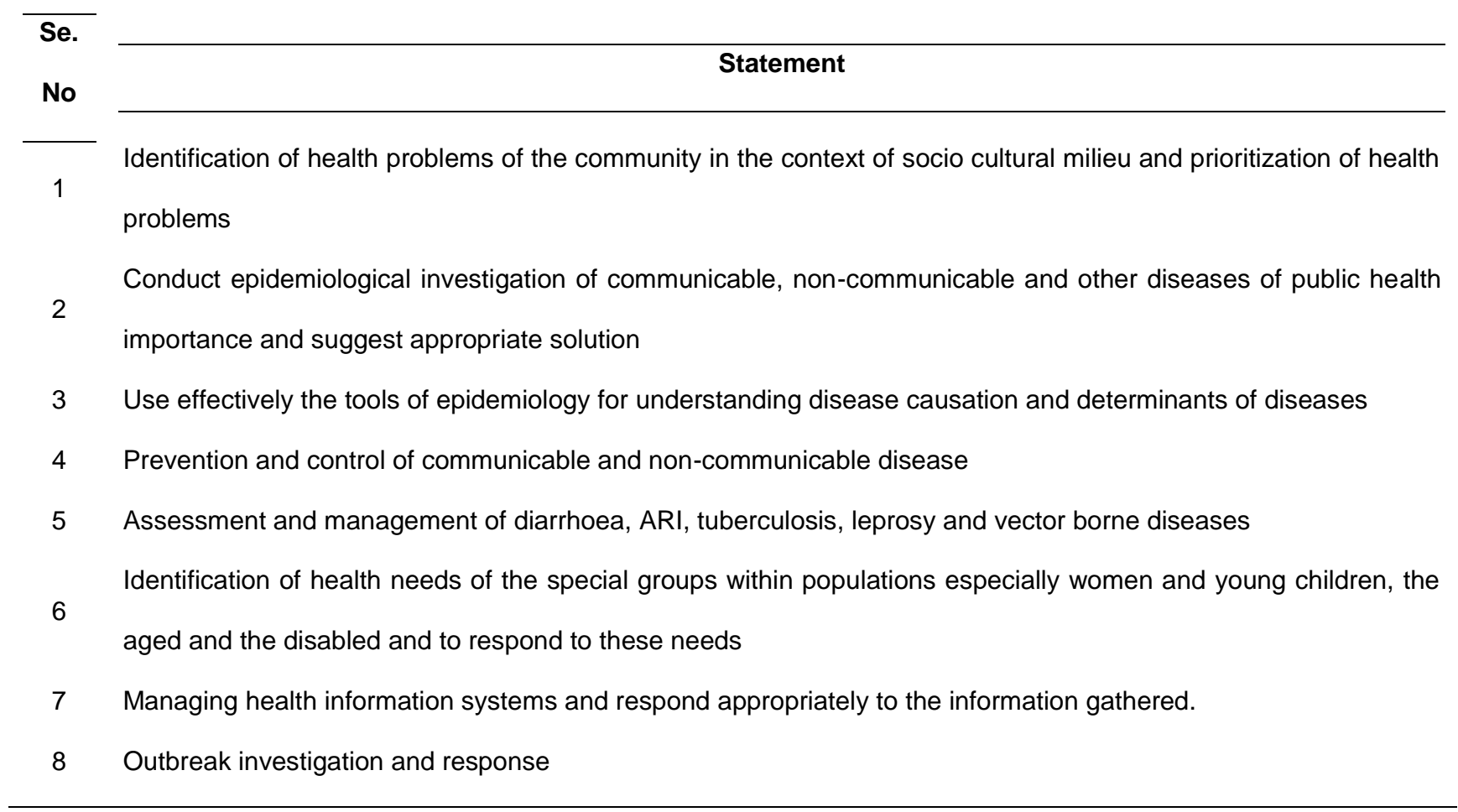




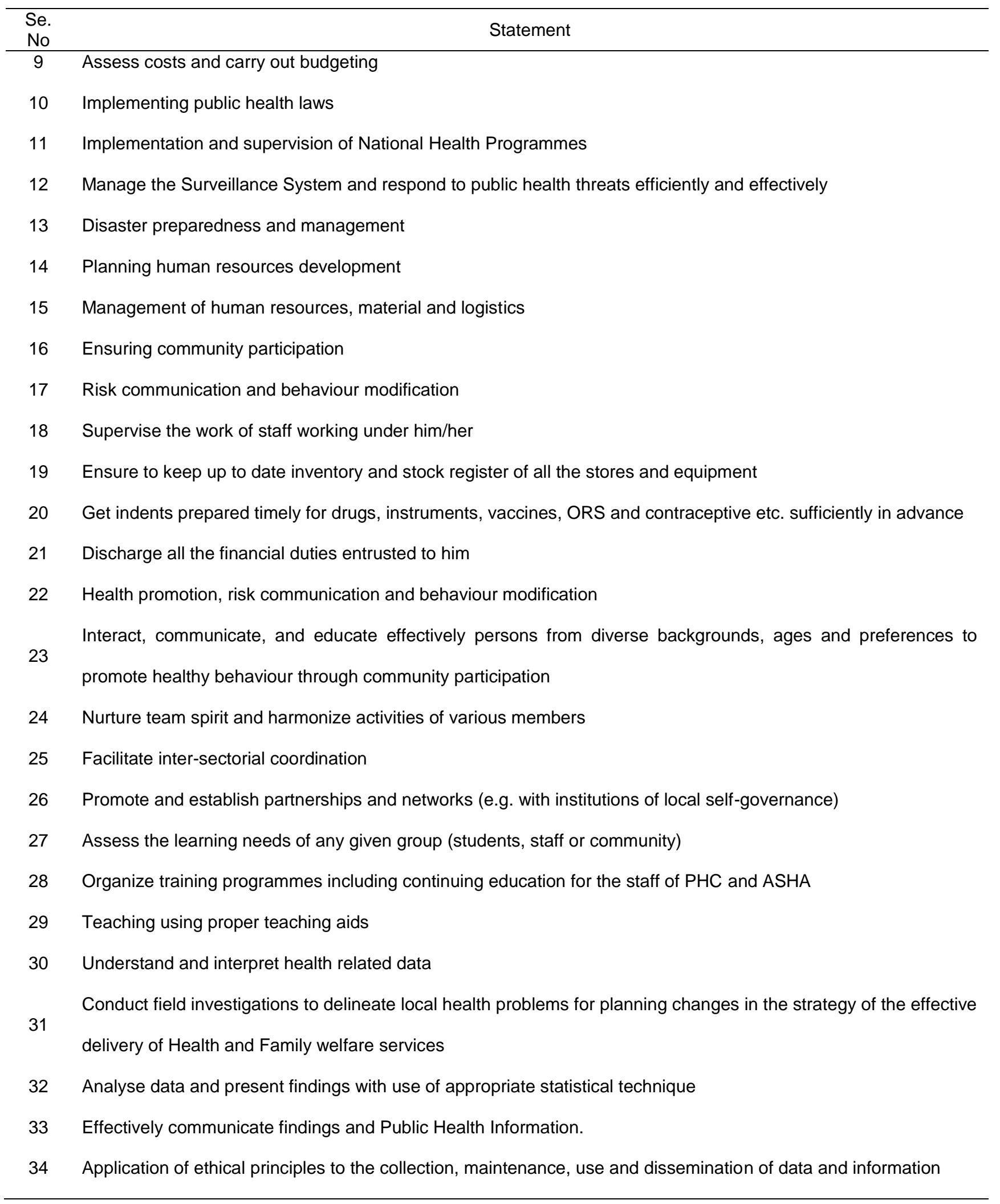


Table 2: links between the MBBS curricular content areas (which can be expected to cover these competencies) and public health functions

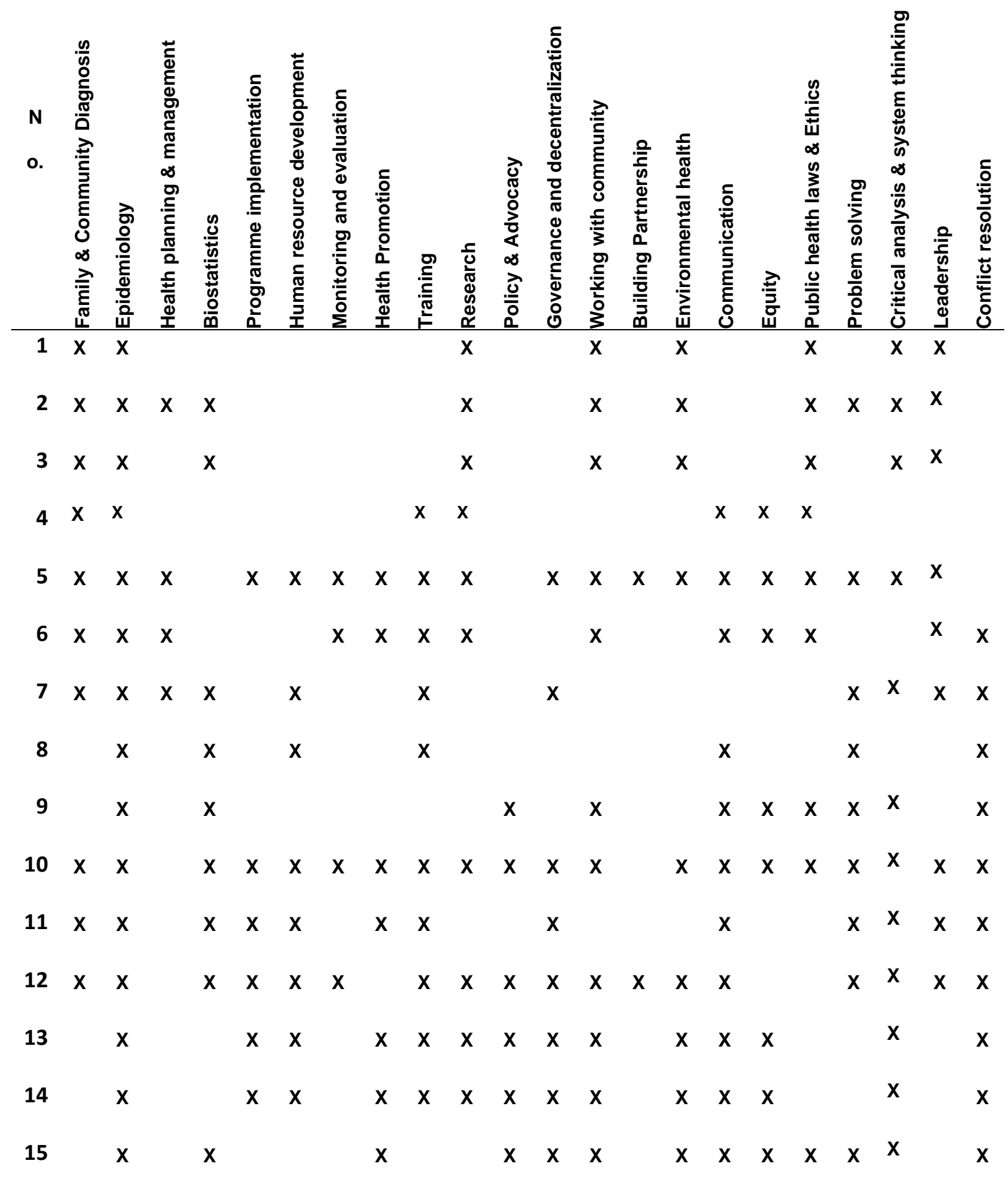




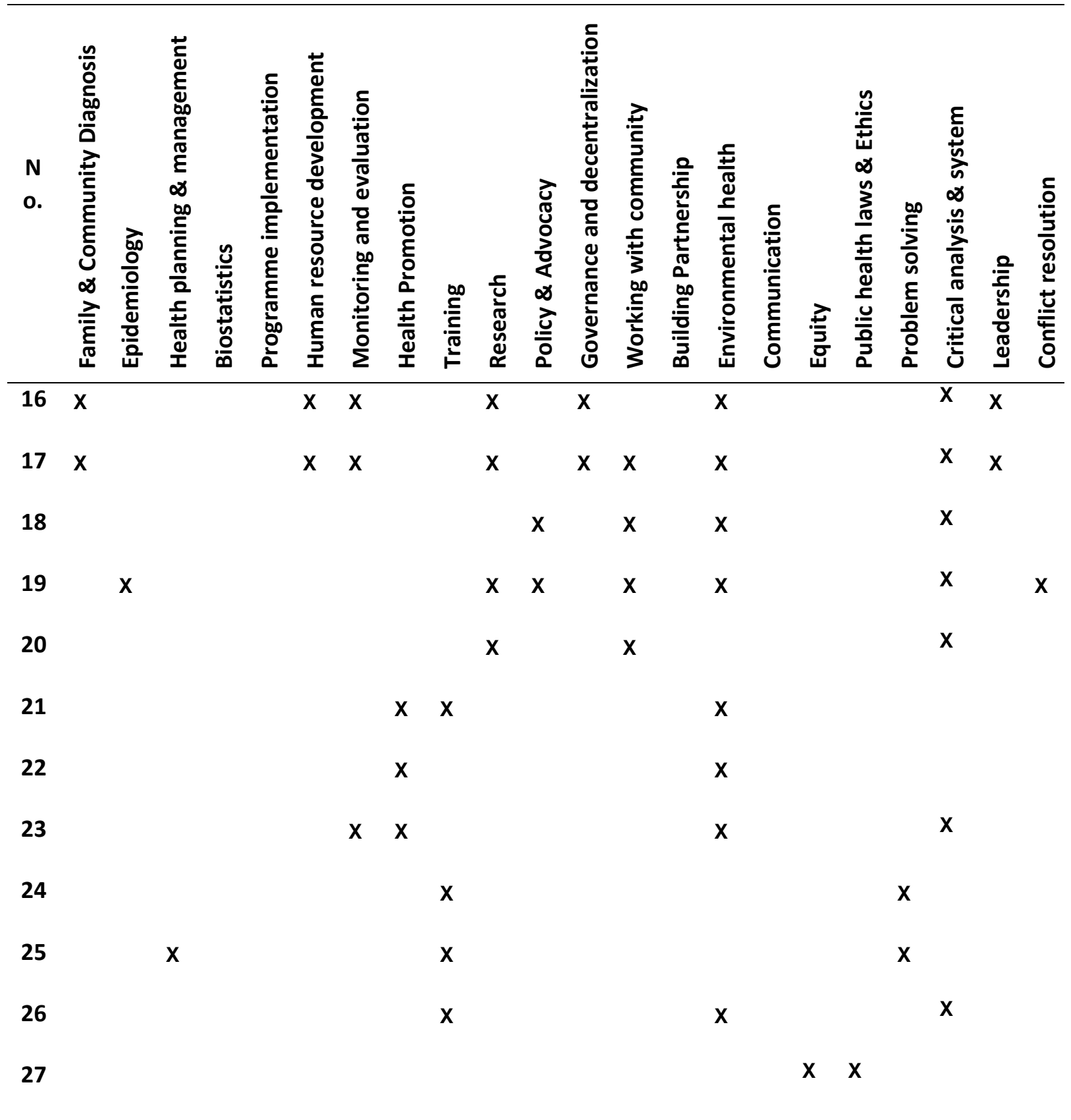

The study identified Communication, Leadership, Equity, Ethics, Problem solving \& Systems thinking, Conflict resolution as Cross-cutting competencies. On the basis of the Miller's triangle, levels of the core competencies to be achieved by MBBS doctors were identified and agreed upon. These results are depicted in table 3 below. 
Table 3: Levels of competency for 'core competency domains'

\begin{tabular}{|c|c|}
\hline \multirow[t]{3}{*}{ Core competency domains } & Level of competency \\
\hline & +++ Shows how \\
\hline & ++ Knows how + knows ) \\
\hline Family \& community diagnosis & ++++ \\
\hline Health planning \& management & +++ \\
\hline Programme implementation & ++ \\
\hline Human resource development & ++ \\
\hline Monitoring \& evaluation & ++ \\
\hline Health promotion & ++ \\
\hline Training & ++ \\
\hline Research & + \\
\hline Policy \& advocacy & ++ \\
\hline Governance \& decentralization & + \\
\hline Working with community & ++ \\
\hline Building partnership & + \\
\hline Environmental science & ++ \\
\hline Epidemiology & ++ \\
\hline Biostatistics & ++ \\
\hline Socio-behavioral science & ++ \\
\hline
\end{tabular}




\section{Discussion}

There has been a series of country level and regional meetings/consultations in India starting from Calcutta conference in 1999 to strengthen the public health system in India with special focus on public health workforce education and curriculum. Most of these consultations were supported by World Health Organization (WHO) Country Office (India) and WHO South East Asia Region (SEAR) Office in close collaboration with the Government of India. Starting with Calcutta Declaration, the need for competency based curricula has been stressed. A Lancet Commission on health care workforce too recommended a system based education to improve the performance of health systems by adapting core professional competencies to specific contexts, while drawing on global knowledge.

A competency framework for public health in the MBBS program is intended to inform the curriculum design which will have to be eventually adopted by institutions and teachers for their future students. Such a framework should clarify and standardize the core and cross-cutting competencies needed by public health workers.

The developed competency framework can potentially strengthen the linkages between public health education and health services delivery system. An essential next step after this study is to develop competency statements for public health competencies to inform curricular contents. It is also important that the methods of assessments incorporated in the public health curricula of various courses match the objectives of the developed competency framework.

Our findings are based on an expert group which had representation from an academic and a health system ministry context. The linkages that were identified between academic domains and the functions were based upon the subjective opinion and subsequent consensus within the expert group. We have however not sought the opinions of the MBBS doctors themselves. Therefore, linking the academic domains to functions is prone to some subjective biases of the group members. As such, the functions list, content areas and competencies proposed by us need to be disseminated at a wider level to be discussed by other stakeholders who could provide alternative perspectives with resultant modifications.

State medical councils may take the leadership to identify and modify the associated functions and initiate work on development of competency frameworks under the guidance of a central expert committee at the national level. It will require persistent advocacy to get a consensus upon the intended competencies for undergraduate medical education. It will also require commitment on the part of universities and faculty to implement the framework.

The transition of health status and emergence of newer health challenges will necessitate a continuous change in public health curricula. The functions and competencies identified by the current study will require periodic reviews and modifications so that the development of competency frameworks becomes a continuous and an iterative process. A five yearly revision of the framework may be a feasible and appropriate option.

Since the current study represents a larger shift towards discussions on competencies and their integration into curricula with the identification of a framework, we believe that now, a solid foundation has been laid for development of competency based public health curricula in our country.

\section{Conflict of Interest}

This work was undertaken by the Indian Public Health Association (IPHA) as part of its efforts towards development of Competency Frameworks for Public Health Professionals in India. The activities were supported by the World Health Organisation (WHO) - Country Office for India.

\section{Contribution of authors}

CSP, SZ, HN conceptualized the study plan; CSP and $S Z$ provided oversight to the project activity; CSP, SZ and HN prepared the first draft of the manuscript; all authors reviewed and contributed to the manuscript 


\section{References}

Ahmed, F. U. (2008) Public health, preventive \& social medicine and community medicine-the name game, Indian Journal of Public Health 52(4), pp. 194-196.

Frenk, J. L., et al. (2010) Health professionals for a new century: transforming education to strengthen health systems in an interdependent world, Lancet, 376(9756), pp.1923-1958.

Gonczi, A., Hager, P. \& Oliver, L. (1990) Establishing Competency-based Standards in the Professions. National Office of Overseas Skills Recognition Research Paper No. I. Canberra, Australian Government Publishing Service.

MCl. (2013). "Medical Council of India." Retrieved 1st October, 2013, from http://www.mciindia.org/.

Negandhi, H., Sharma, K. \& Zodpey, S. P. (2010) "How can departments of community medicine shape the future of public health education in India, Indian Journal of Public Health 54(4), pp.184-189.

Negandhi, H., Sharma, K. \& Zodpey, S. P. (2012) History and evolution of public health education in India, Indian Journal of Public Health 56(1), pp. 1216.

Public Health Agency of Canada (2008) Core competencies for public health in Canada.

Shewade, H. D., Jeyashree, K. \& Chinnakali, P. (2014) Reviving community medicine in India: The need to perform our primary role, International Journal of Medicine and Public Health 4, pp. 29-32.

Whittaker, P. J., Pegorie, M., Read, D., Birt, C. A. \& Foldspang, A. (2010) Do academic competencies relate to 'real life' public health practice? A report from two exploratory workshops, European Journal of Public Health 20(1), pp. 8-9.

Zodpey, S., Sharma, K. \& Negandhi, H. (2011) Master of Public Health programs in India New Delhi, Public Health Foundation of India. 